\title{
Undergraduate hematology - a more integrated approach
}

This article was published in the following Dove Press journal:

Advances in Medical Education and Practice

23 November 2016

Number of times this article has been viewed

\section{Matteo A Di Carlofelice* Jack FT Cope*}

Faculty of Medicine, Imperial College London, London, UK

*These authors contributed equally to this work
Correspondence: Matteo A Di Carlofelice Faculty of Medicine, Imperial College London, Level 2, Faculty Building, South Kensington Campus, London SW7 2AZ, UK

Tel +44 77 I 358573 |

Email madII3@ic.ac.uk

Jack FT Cope

Faculty of Medicine, Imperial College London, Level 2, Faculty Building, South Kensington Campus, London SW7 2AZ, UK

Tel +44 79 I26I I228

Email jack.copel3@ic.ac.uk

\section{Dear editor}

As fellow medical students we read with great interest the article by Mandan et $\mathrm{al}^{1}$ proposing a dedicated hematology rotation. The authors highlight a gap in clinical hematology teaching, particularly compared to "conventional rotations". ${ }^{1}$ Their suggestion has merits and we agree with most of the points raised; however, propose instead for us to build on current teaching as opposed to establishing a new rotation.

The integration of theoretical and practical learning was concluded to be beneficial to both teacher and student by Wrenn and Wrenn. ${ }^{2}$ In the original article it is mentioned that "clinical experience allows students to comprehend and apply this knowledge in practice, enabling the all-important integration of their learning". ${ }^{1}$ As we agree that hematology overlaps with other specialties and therefore requires a thorough understanding, we value how a clinical attachment would be useful to solidify lecture-based teaching.

Despite the concept of this rotation being justifiable, we believe there are barriers to this being achieved:

First, would there not be an obligation to do the same for other specialties which you could argue warrant more attention? For example, the statistical brief by Elixhauser and Owens ${ }^{3}$ found the top reason for hospitalizations through the emergency department for pneumonia. There is currently however no compulsory respiratory medicine attachment.

Second, the article mentions that "conventional rotations such as cardiology, surgery, and psychiatry" are "offered", but a hematology rotation is not "mandatory". Although these "conventional rotations" are available, the implication that they are mandatory is not true. Instead, it would seem as if "conventional" rotation delegation is based more on available resources and randomization.

Even with competent teaching, studying a medical degree involves self-directed learning and motivation. This is in order to fill inevitable gaps in knowledge that form due to the complexity of the subject studied. These "gaps" would be present regardless of a rotation in hematology, as no two medical students will see the same patients.

Third, it is suggested that students should have protected time with specialists such as pediatric hematologists. Currently $1.6 \%$ of registered consultants are hematologists ${ }^{4}$ and fewer are super-specialized. Finding this protected time would be challenging if it is compulsory for $\sim 7000$ medical students enrolling each year. ${ }^{5}$ Also, do the authors suggest 
that students should have protected time with similar specialists in other departments? If not, this appears disproportional.

It would perhaps be more modern to shift the curriculum away from hospital specialist learning to primary care, considering the Department of Health's target for $50 \%$ of medical graduates to become general practitioners. ${ }^{6}$

Fourth, we can envision how junior doctors may become better equipped to order appropriate investigations for patients and understand results if pathology is more integrated into clinical teaching. The authors go on to say that students should spend more time in laboratories during attachments to acquire the laboratory skills required by foundation doctors. ${ }^{1}$ A factor that may need to be taken into consideration is whether the university encourages BSc intercalation. Although, not all BSc courses contain laboratory-based components, students may have already acquired these skills and thus more compulsory laboratory time may seem less fruitful than clerking patients and improving their clinical skills.

Finally, medical school pathology courses already cover a vast amount of clinical hematology. This builds well on previous preclinical hematology teaching and cases students have come across in their existing clinical rotations.

Integrated teaching can be achieved by assigning assessed tasks for students, to complete during their rotations. For example, asking students to analyze a patient's blood and pathology results, and to link these to their overall clinical picture.

Students could discuss their reports in multidisciplinary team style meetings with peers, where they could learn from each other and receive guidance from a supervisor.

This form of self-directed study gives students the opportunity to research the aforementioned "gaps", particularly regarding more specialist areas, for example, pediatric-hematology.
In conclusion, we agree with Mandan et al's opinion ${ }^{1}$ that a hematology placement would provide students with teaching in an area that is currently neglected.

However, with the limited number of hematology departments, the difficulty of fitting in another attachment, and the presence of competing specialties we feel this is not the best option. Instead, by improving the integration of current methods and building on these, we believe that students can gain a better understanding of not only hematology but also how it fits into a complex clinical picture.

\section{Disclosure}

The authors report no conflicts of interest in this communication.

\section{References}

1. Mandan J, Sidhu HS, Mahmood A. Should a clinical rotation in hematology be mandatory for undergraduate medical students? Adv Med Educ Pract. 2016;7:519-521.

2. Wrenn J, Wrenn B. Enhancing learning by integrating theory and practice. Int J Teach Learning Higher Edu. 2009;21(2):258-265.

3. Elixhauser A, Owens P. Reasons for being admitted to the hospital through the emergency department. In: Healthcare Cost and Utilization Project (HCUP) Statistical Briefs. Rockville, MD, USA: Agency for Healthcare Research and Quality; 2003. Available from: http://www.ncbi.nlm.nih. gov/books/NBK63506/. Accessed September 19, 2016.

4. General Medical Council. List of registered medical practitioners statistics. Available from: http://www.gmc-uk.org/doctors/register/ search_stats.asp. Accessed September 19, 2016.

5. Higgs J. Pre-clinical medicine (A1) UCAS application and acceptance statistics, 2007-2014. Available from: https://en.wikipedia.org/wiki/ File:Pre-Clinical_Medicine_(A1)_UCAS_application_and_accpetances_ statistics,_2007_-_2014.jpg. Accessed September 20, 2016.

6. NHS England, NHS Improvement (Monitor and the NHS Trust Development Authority), Care Quality Commission (CQC), Health Education England (HEE), National Institute of Health and Care Excellence (NICE), Public Health England (PHE). Delivering the Forward View: NHS Planning Guidance 2016/17-2020/21. National Health Service Commissioning Board (Version 2), 2015.

Dove Medical Press encourages responsible, free and frank academic debate. The content of the Advances in Medical Education and Practice 'letters to the editor' section does not necessarily represent the views of Dove Medical Press, its officers, agents, employees, related entities or the Advances in Medical Education and Practice editors. While all reasonable steps have been taken to confirm the content of each letter, Dove Medical Press accepts no liability in respect of the content of any letter, nor is it responsible for the content and accuracy of any letter to the editor.

\section{Publish your work in this journal}

Advances in Medical Education and Practice is an international, peerreviewed, open access journal that aims to present and publish research on Medical Education covering medical, dental, nursing and allied health care professional education. The journal covers undergraduate education, postgraduate training and continuing medical education including emerging trends and innovative models linking education, research, and health care services. The manuscript management system is completely online and includes a very quick and fair peer-review system. Visit http://www.dovepress.com/testimonials.php to read real quotes from published authors. 